\title{
VALIDITY OF DIGITAL PANORAMIC RADIOGRAPHY IN POST-MARSUPIALIZATION SIZE REDUCTION ASSESSMENT OF MANDIBULAR CYSTIC LESIONS
}

\author{
Hamed Gad * and Ahmed M. Bakry **
}

\begin{abstract}
Objectives: The purpose of this study was to evaluate the accuracy of digital panoramic radiography (DP) in assessment of size reduction following the marsupialization of mandibular cystic lesions.

Methodology: 10 patients those were exhibited mandibular odontogenic cystic lesions at the molar/ ramus areas were selected. These lesions were included; 7 mandibular odontogenic keratocystic tumors (OKCT) and 3 mandibular unicystic ameloblastoma(UAB). All lesions were examined pre-marsupialization and during the follow up periods with Multi-slice CT (MSCT) Scan (that used as a gold standard) and digital panoramic radiography.
\end{abstract}

Results: There was a statistically significant difference between the (MSCT) and digital panorama (DP) in detecting the actual size reduction of the cystic lesions resulted from bone deposition after marsupialization. MSCT showed statistically significantly higher prevalence of validity and clearly interpretation than modality of the digital panoramic radiography.

Conclusion: The digital panoramic radiography alone is insufficient tool for assessment, evaluation and follow up of the post-marsupialization size reduction progress of mandibular odontogenic cystic lesions, and subsequently this reliance might be lead to erroneous professional decision related to real size reduction of these types of lesions.

\section{INTRODUCTION}

Odontogenic cystic lesions can be treated by complete surgical enucleation with or without peripheral osteotomy or by a gradual diminishing process using the tendency of peripheral bone to centripetally grow into the cavity center after relief of the internal hydrostatic pressure caused by the cystic content. The term marsupialization is used for the surgical technique of fenestration of the cystic wall and lining and suturing the inner cystic lumen with the oral mucosa, thus interconnecting the cyst cavity with the oral cavity.,

* Lecturer of Oral and Maxillofacial Surgery, Faculty of Dentistry, Minia University.

** Lecturer of Oral and Maxillofacial Radiology, Faculty of Dentistry, Minia University. 
Digital panoramic radiography (DP) has been widely used for obtaining a comprehensive overview of the maxillofacial complex. One of the limiting factors in the clinical use of DR is the uncertainty regarding the actual dimensions of structures given their radiographic appearance. ${ }^{3-6}$

MSCT is one of the most useful modalities for assessing jaw bone lesions. It clearly depicts soft tissues and hard tissues without superimposition of anatomical structures. ${ }^{79}$ Moreover, MSCT scans exhibit no magnification and no geometric distortion. Within the limits of its spatial resolution, MSCT is considered more reliable than conventional projection radiography as a morphometric tool. ${ }^{10}$ Although a number of studies have shown that measured dimensions on DP are reliable, ${ }^{1,6}$ there is no clinical comparison between measured dimensions on digital DP and those obtained from three-dimensional structures. The purpose of this study was to evaluate the accuracy of digital panorama DP in assessing the size reduction of cystic cavity after marsupialization of mandibular molar/ramus area lesions compared with those measured on MSCT images.

\section{Methodology}

The current study was conducted on 10 patients, aged ranged from 22 to 60 years (average age, 32 years), of both gender( 5 men and 5 women). These patients were suffered from 10 mandibular cystic lesions (7 OKCTs and 3 UABs) at the mandibular ramus- molar region. These lesions were undergone marsupialization and followed up tile 12 months post-marsupialization. The diagnoses, management and follow up were accomplished at the Out Patients Clinic of the Oral and Maxillofacial Surgery Department (OMFSD), Minia University Dental Hospital (MUDH).

All patients had been examined preoperatively using digital panoramic radiographs, and MSCTs.
All marsupialization procedures were operated in an outpatient clinic at (OMFSD) and performed under local anesthesia with vasoconstrictors. Aspiration was performed firstly to confirm the diagnosed cystic cavities, and then marsupialization was performed simultaneously with incisional biopsy. The cysts lining were exposed after limited osteoplasty of the buccal bone plate. Opening of an appropriate sized window (not less than $1 \mathrm{~cm}$ in diameter) into the each cystic cavity was performed. The opening windows were kept opened by suturing of the periphery of each cyst lining to the oral mucosa and each cavity was packed with a gauze pack which changed daily by patient himself for the first week of post-marsupialization. Digital Panoramic radiographs and MSCT radiographs were repeated every 3 months for evaluation of cystic sizes reduction and improvement tile the end of the postmarsupialization follow up periods. (figure 1) During follow up periods, the borders of the lesions as well as the entire cystic views were assessed on MSCT and digital panorama. Mean relative differences between the observed qualitative values on digital panorama and MSCT were analyzed for every case. The assessment achieved premarsupialization and (three months, six months, nine months and one year) post -marsupialization. Table 1,2.

TABLE (1) Scoring system of the clinical radiographic interpretation

\begin{tabular}{|c|l|}
\hline 1 & Clearly seen \\
\hline 2 & Seen \\
\hline 3 & Hazy of out line \\
\hline 4 & Not clearly seen \\
\hline 5 & Disappear \\
\hline
\end{tabular}


TABLE (2) Numerical evaluation of MSCT and DP pre-operatively and during one year follow up

\begin{tabular}{|c|c|c|c|c|c|c|c|c|c|c|c|}
\hline \multirow{3}{*}{$\begin{array}{c}\text { No. } \\
\\
1 \\
\end{array}$} & \multirow{3}{*}{$\begin{array}{l}\text { Preoperative } \\
\text { Size in } \mathrm{mm}^{2} \\
180\end{array}$} & \multicolumn{2}{|c|}{$\begin{array}{c}\text { Preoperative } \\
\text { evaluation }\end{array}$} & \multicolumn{2}{|c|}{$\begin{array}{c}3 \text { months } \\
\text { postoperatively }\end{array}$} & \multicolumn{2}{|c|}{$\begin{array}{c}6 \text { month } \\
\text { postoperatively }\end{array}$} & \multicolumn{2}{|c|}{$\begin{array}{c}9 \text { month } \\
\text { postoperatively }\end{array}$} & \multicolumn{2}{|c|}{$\begin{array}{c}12 \text { month } \\
\text { postoperatively }\end{array}$} \\
\hline & & $\mathrm{Ct}$ & & $\mathrm{Ct}$ & opt & $\mathrm{Ct}$ & opt & $\mathrm{Ct}$ & opt & $\mathrm{Ct}$ & opt \\
\hline & & 1 & 2 & 1 & 2 & 1 & 3 & 1 & 3 & 1 & 5 \\
\hline 2 & 920 & 1 & 1 & 1 & 1 & 1 & 2 & 1 & 2 & 1 & 3 \\
\hline 3 & 4500 & 1 & 1 & 1 & 1 & 1 & 2 & 1 & 2 & 1 & 3 \\
\hline 4 & 500 & 1 & 1 & 1 & 2 & 1 & 3 & 1 & 3 & 1 & 4 \\
\hline 5 & 180 & 1 & 2 & 1 & 2 & 1 & 3 & 1 & 3 & 1 & 5 \\
\hline 6 & 850 & 1 & 1 & 1 & 2 & 1 & 3 & 1 & 3 & 1 & 3 \\
\hline 7 & 700 & 1 & 1 & 1 & 2 & 1 & 2 & 1 & 3 & 1 & 4 \\
\hline 8 & 225 & 1 & 1 & 1 & 2 & 1 & 4 & 1 & 4 & 1 & 5 \\
\hline 9 & 950 & 1 & 1 & 1 & 2 & 1 & 2 & 1 & 3 & 1 & 3 \\
\hline 10 & 1200 & 1 & 1 & 1 & 2 & 1 & 2 & 1 & 2 & 1 & 3 \\
\hline
\end{tabular}

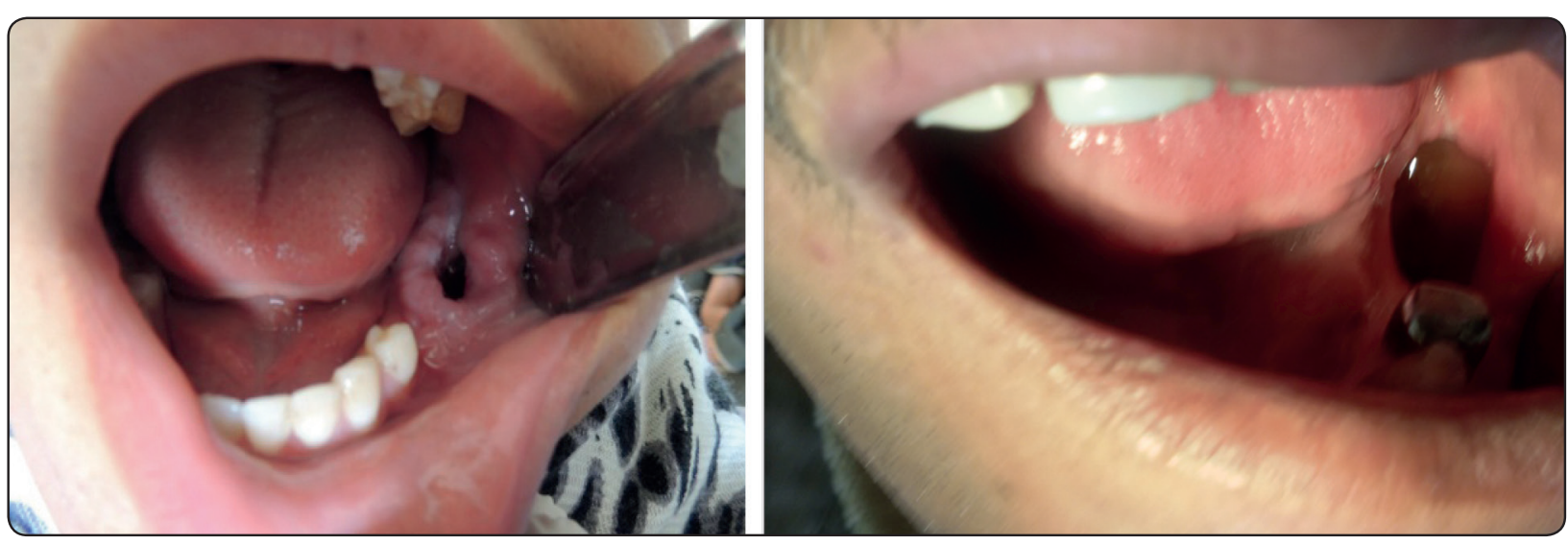

Fig. (1) A photographic views shows the opening of marsupialization of different two cases.

\section{Statistical Analysis}

Scores were represented as frequencies (n) and percentages $(\%)$. Friedman's test was used to compare between the two modalities as well as to study the changes by time in scores detected by DP modality. Spearman's correlation coefficient was used to determine correlation between lesion size and different scores. Sensitivity, Specificity and Diagnostic accuracy were calculated as follows:

Sensitivity $(\%)=$ True positive $\mathrm{x} 100$

True positive + False negative
Specificity $(\%)=$ True negative x 100

False positive + True negative

Diagnostic accuracy $(\%)=$

$$
\text { True positive }+ \text { True negative } \times 100
$$

Total number

The significance level was set at $\mathrm{P} \leq 0.05$. Interobserver agreement analysis was performed with IBM ${ }^{\circledR}$ SPSS $®$ Statistics Version 20 for Windows.

\footnotetext{
${ }^{\circledR}$ IBM Corporation, NY, USA.

${ }^{\circledR}$ SPSS, Inc., an IBM Company.
} 


\section{RESULTS}

\section{Comparison between CT and DP modalities}

Pre-operatively, there was no statistically significant difference between the two modalities in detecting lesion.

After 3, 6, 9 as well as 12 months, there was a statistically significant difference between the two modalities in detecting lesion. Multi-slice CT showed statistically significantly higher prevalence of (Clearly seen lesion) than DP modality. Table (3) $\&$ figure 2

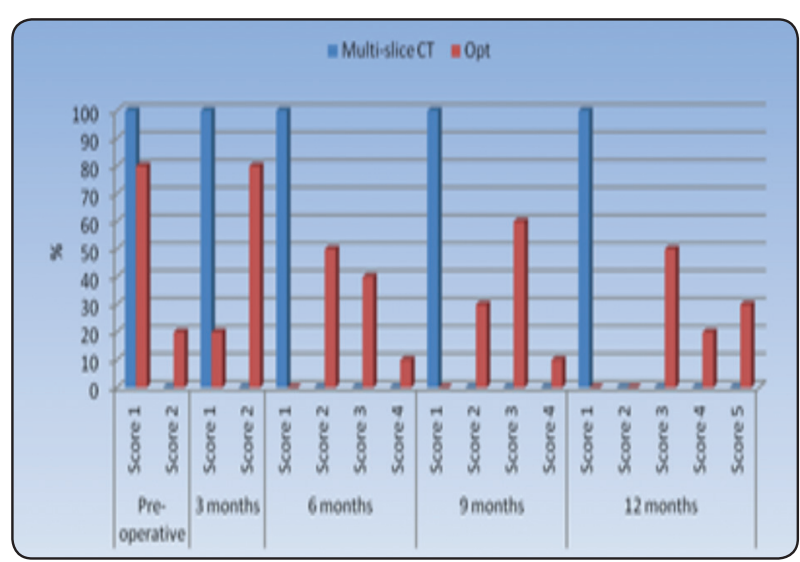

Fig. (2) Bar chart representing comparison between the two modalities

TABLE (3) Frequencies (n), percentages (\%) and results of Friedman's test for comparison between lesion detection by the two modalities

\begin{tabular}{|c|c|c|c|c|c|c|}
\hline \multirow[b]{2}{*}{ Time } & \multirow[b]{2}{*}{ Score } & \multicolumn{2}{|c|}{ Multi-slice CT } & \multicolumn{2}{|c|}{ Opt } & \multirow{2}{*}{ P-value } \\
\hline & & $\mathrm{n}$ & $\%$ & $\mathrm{~N}$ & $\%$ & \\
\hline \multirow{2}{*}{ Pre-operative } & 1 (Clearly seen) & 10 & 100.0 & 8 & 80.0 & \multirow{2}{*}{0.157} \\
\hline & 2 (Seen) & 0 & 0.0 & 2 & 20.0 & \\
\hline \multirow{2}{*}{3 months } & 1 (Clearly seen) & 10 & 100.0 & 2 & 20.0 & \multirow{2}{*}{$0.005^{*}$} \\
\hline & 2 (Seen) & 0 & 0.0 & 8 & 80.0 & \\
\hline \multirow{4}{*}{6 months } & 1 (Clearly seen) & 10 & 100.0 & 0 & 0.0 & \multirow{4}{*}{$0.002 *$} \\
\hline & 2 (Seen) & 0 & 0.0 & 5 & 50.0 & \\
\hline & 3 (Hazy) & 0 & 0.0 & 4 & 40.0 & \\
\hline & 4 (Not clearly seen) & 0 & 0.0 & 1 & 10.0 & \\
\hline \multirow{4}{*}{9 months } & 1 (Clearly seen) & 10 & 100.0 & 0 & 0.0 & \multirow{4}{*}{$0.002 *$} \\
\hline & 2 (Seen) & 0 & 0.0 & 3 & 30.0 & \\
\hline & 3 (Hazy) & 0 & 0.0 & 6 & 60.0 & \\
\hline & 4 (Not clearly seen) & 0 & 0.0 & 1 & 10.0 & \\
\hline \multirow{5}{*}{12 months } & 1 (Clearly seen) & 10 & 100.0 & 0 & 0.0 & \multirow{5}{*}{$0.002 *$} \\
\hline & 2 (Seen) & 0 & 0.0 & 0 & 0.0 & \\
\hline & 3 (Hazy) & 0 & 0.0 & 5 & 50.0 & \\
\hline & 4 (Not clearly seen) & 0 & 0.0 & 2 & 20.0 & \\
\hline & 5 (Disappear) & 0 & 0.0 & 3 & 30.0 & \\
\hline
\end{tabular}




\section{Changes by time as detected by DP modality}

There was a statistically significant change by time in different scores. There was a decrease in prevalence of Score 1 after 3, 6, 9 as well as 12 months. There was an increase in Score 2 after 3 months then a decrease was observed after 6 months, 9 as well as 12 months. There was an increase in Score 3 after 6 months as well as 9 months then a decrease was observed after 12 months. There was an increase in Score 4 after 6 months which remained unchanged after 9 months then increased after 12 months. There was an increase in Score 5 after 12 months. Table 4

\section{Correlation between lesion size and scores of DP modality}

There was a statistically significant inverse (negative) correlation between lesion size and scores of DP modality pre-operatively, after 6, 9 as well as 12 months. After 3 months, there was no statistically significant correlation between lesion size and scores of DP modality. Table 5

TABLE (4) Frequencies (n), percentages (\%) and results of Friedman's test for comparison between lesion detection at different time periods by DP modality

\begin{tabular}{|c|c|c|c|c|c|c|c|c|c|c|c|}
\hline \multirow[b]{2}{*}{ Score } & \multicolumn{2}{|c|}{ Pre-operative } & \multicolumn{2}{|c|}{3 months } & \multicolumn{2}{|c|}{6 months } & \multicolumn{2}{|c|}{9 months } & \multicolumn{2}{|c|}{12 months } & \multirow{2}{*}{ P-value } \\
\hline & $\mathrm{N}$ & $\%$ & $\mathrm{~N}$ & $\%$ & $\mathrm{~N}$ & $\%$ & $\mathrm{~N}$ & $\%$ & $\mathrm{n}$ & $\%$ & \\
\hline 1 (Clearly seen) & 8 & 80.0 & 2 & 20.0 & 0 & 0.0 & 0 & 0.0 & 0 & 0.0 & \multirow{5}{*}{$<0.001 *$} \\
\hline 2 (Seen) & 2 & 20.0 & 8 & 80.0 & 5 & 50.0 & 3 & 30.0 & 0 & 0.0 & \\
\hline 3 (Hazy) & 0 & 0.0 & 0 & 0.0 & 4 & 40.0 & 6 & 60.0 & 5 & 50.0 & \\
\hline 4 (Not clearly seen) & 0 & 0.0 & 0 & 0.0 & 1 & 10.0 & 1 & 10.0 & 2 & 20.0 & \\
\hline 5 (Disappear) & 0 & 0.0 & 0 & 0.0 & 0 & 0.0 & 0 & 0.0 & 3 & 30.0 & \\
\hline
\end{tabular}

*: Significant at $P \leq 0.05$

TABLE (5) Results of Spearman's correlation coefficient for the correlation between lesion size and scores of DP modality

\begin{tabular}{|c|c|c|c|c|c|}
\hline & Pre-operative & 3 months & 6 months & 9 months & 12 months \\
\hline \multirow{2}{*}{ Correlation coefficient } & -0.698 & -0.524 & -0.780 & -0.717 & -0.924 \\
\cline { 2 - 5 } P-value & $0.025^{*}$ & 0.120 & $0.008^{*}$ & $0.020^{*}$ & $<0.001^{*}$ \\
\hline
\end{tabular}

*: Significant at $\mathrm{P} \leq 0.05$ 


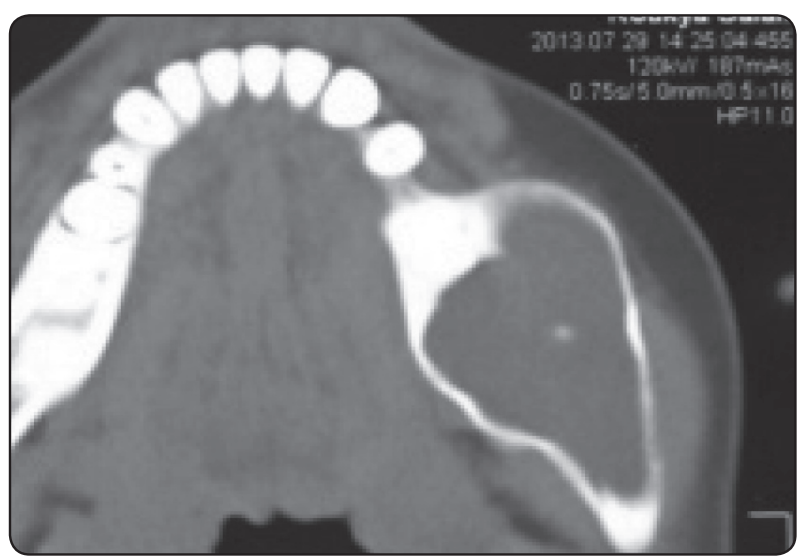

Fig. (3) Pre-marsupialization cropped MSCT image shows the UAB lesion with well defined border.

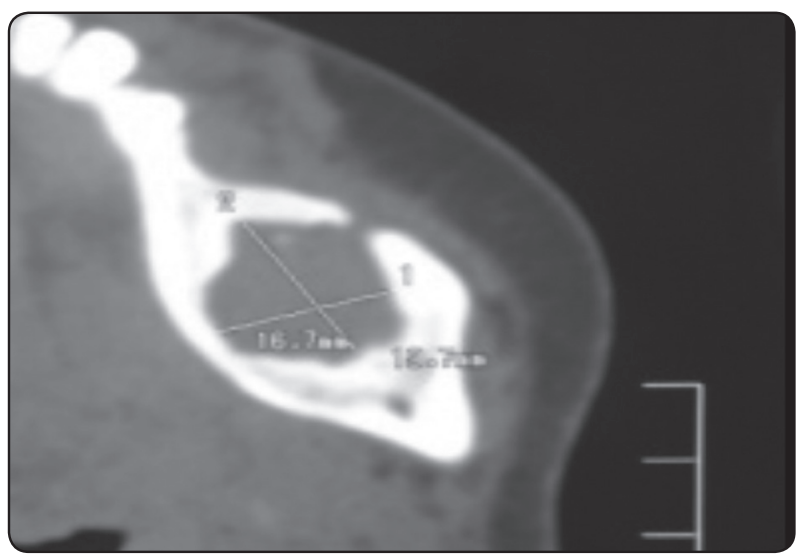

Fig. (5) 6 month post marsupialization cropped MSCT image shows well defined border of the reduced lesion

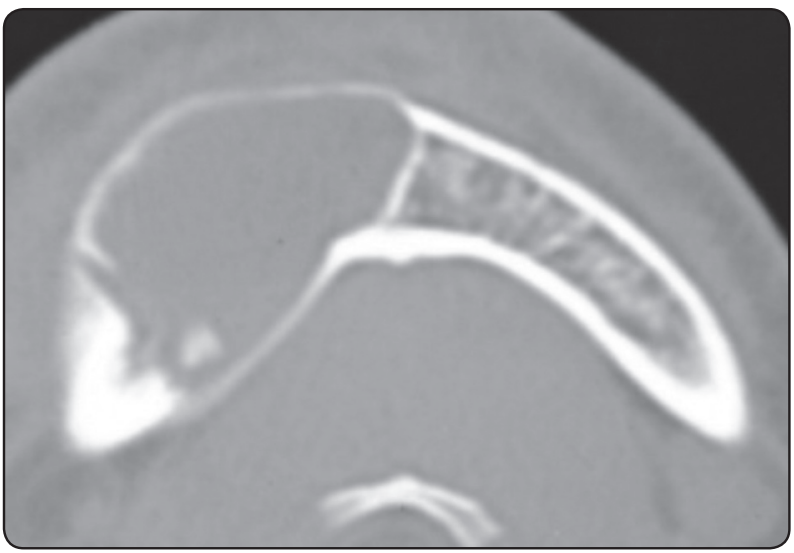

Fig. (7) Pre-marsupialization cropped MSCT image of OKCT lesion

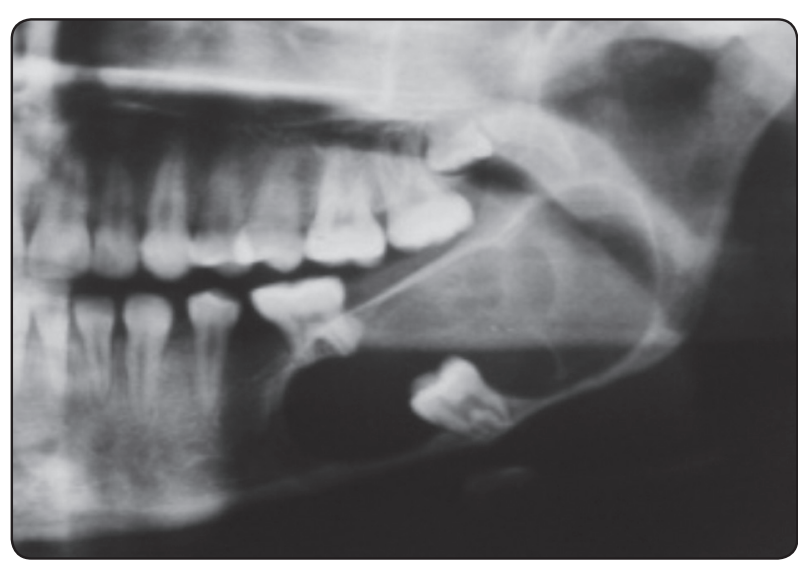

Fig. (4) Premarsupialization cropped digital panoramic image shows the UAB lesion with well defined border in the same case in fig.3.

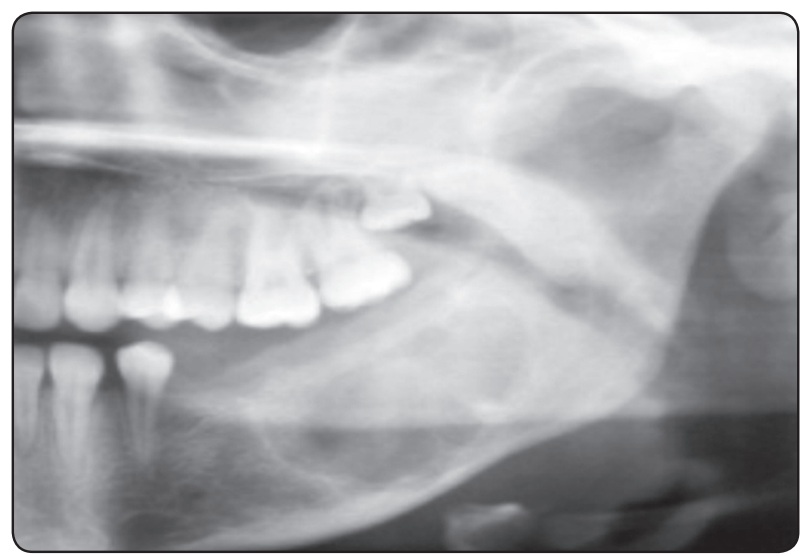

Fig. (6) 6 month post marsupialization cropped digital panoramic image shows ill well defined border and bad quality of the cavity of the lesion in the same case of figure 5

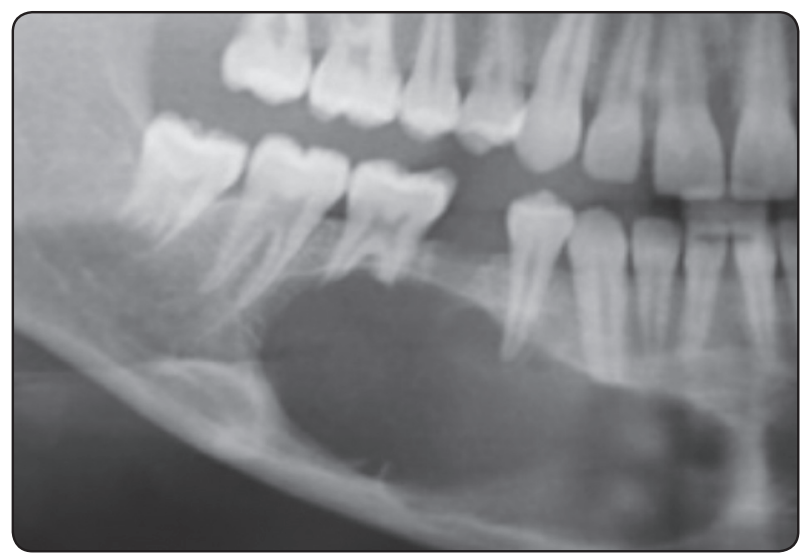

Fig. (8) Preoperative cropped digital panoramic image shows a well defined margin in the same case of figure 7. 


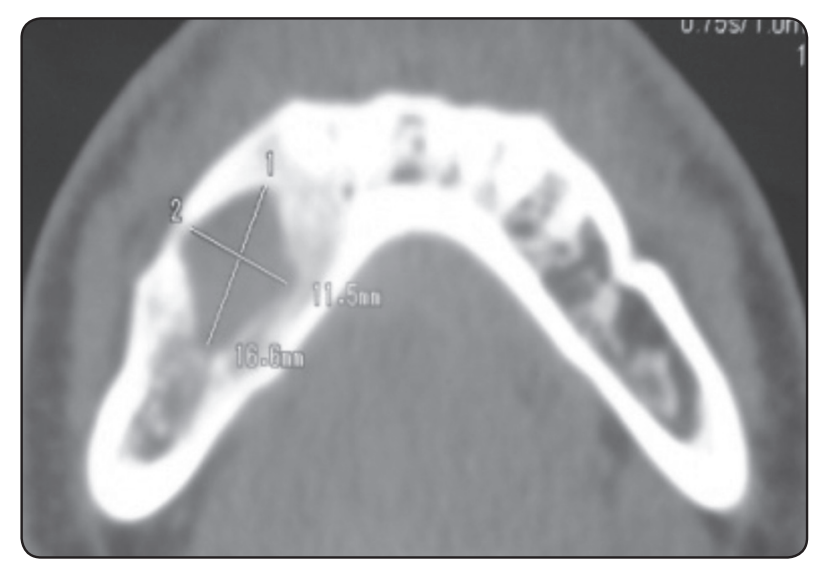

Fig. (9) 9 months of post marsupialization cropped MSCT image shows incomplete healing and clearly seen view

\section{DISCUSSION}

Marsupialization is a surgical technique by which a window is produced in the wall of the cyst to relieve the intra-cystic pressure and so enable the cavity to decrease slowly in size. This approach was advocated by Partsch in $1892^{1}$, has become known as the Partsch I technique. Later, when sufficient bone has been deposited to protect the particular structures that were at risk, complete enucleation is carried out as a second stage procedure with primary wound closure. ${ }^{2}$ The cyst outline, as indicated by the topography of the bony defect, was very clearly demonstrated by the axial and buccolingual images, summation of which facilitates the interpretation of structures in three dimensions. The same points have been made on the use of CT in periodontal diseases..$^{11-14}$

The idea of this study imitative to the authors during evaluation of postmarsupialization size reduction progress of the selected mandibular cystic lesions during interpretation MSCT and DP radiography of the same lesions at the same intervals. Fortunately, the authors founded a different substantial observational finding in serial views of digital panorama of these lesions compared with those viewed in MSCT at the same sessions. Then, the authors created a scoring a table

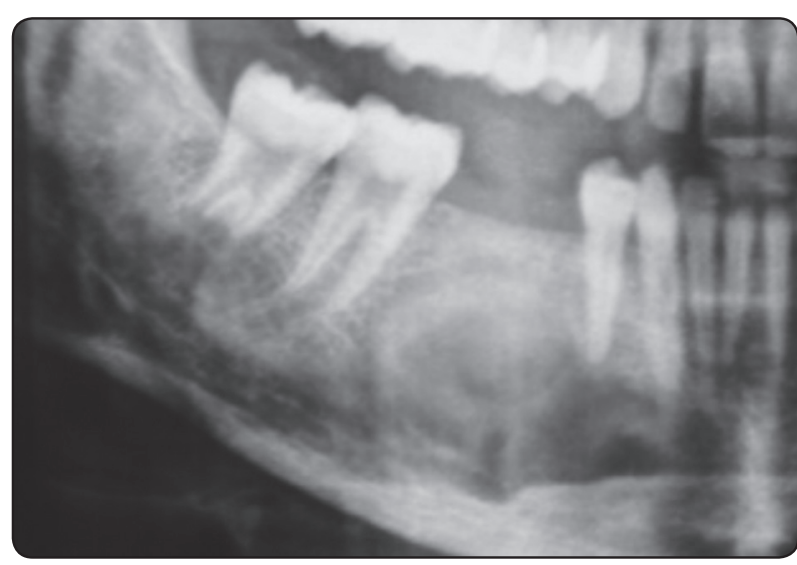

Fig. (10) 9 month A post-marsupialization cropped digital panoramic image shows ill-defined border determination of the same case of figure 9 .

of these qualitative differences during examination of both DP and MSCT of the subsequent cases and subjected to statistically analyzing.

Huang et al ${ }^{15}$ study concluded that CT has become a widely used modality and has even been recommended as the method of choice for surgical planning. Panoramic radiographs show limitations in the detection of bony structures when solely used. The routine use of dental CT scanning as a diagnostic method is at this time constrained due to the relatively high level of radiation doses, as well as the time and labor the procedure requires with resulting implications for cost factors ${ }^{16}$.

Pogre et $\boldsymbol{a} \mathbf{l}^{17}$ in their study conclude that: CT is a more precise method to evaluate cystic lesions and postoperative bone regeneration over time. But they also said that the results obtained with the computedassisted method for the evaluation of the healing processes on panoramic radiographs were almost the same as those from CT. our results compatible with his $1^{\text {st }}$ conclusion and inconvenient with the second conclusion.

Thomas $^{3}$ depend totally on panoramic radiographic view during evaluation of twenty-five cysts and cyst like lesions in 25 patients were treated with decompression followed by enucleation and 
curettage but he concluded that; the availability of 3-dimensional imaging with cone-beam computer tomography will allow for more accurate size determination before and after decompression. This conclusion is nearly consistent with the our study outcome.

Chuencho et $\boldsymbol{a l ^ { 1 8 }}$ on their study concluded that. The measurements of the horizontal and vertical dimensions of bone lesions in the posterior mandible on panoramic radiographs are accurate when the margins of the lesion are well defined only. This is consistent with our finding where the quality of new deposited bone around the periphery of cystic cavity not fully mineralized like the adjacent normal bone. This well lead to confusion in detection of accurate cavity sizes during the follow up period after marsupialization. Meanwhile CT, is a non-invasive imaging method allowing three dimensional measurements, depicts both soft tissue and hard tissue changes without superimposition of anatomical structures.

Several investigators have reported that the horizontal distance measured on DP is unreliable owing to non-linear variation in the magnification at different object depths, whereas vertical distance is relatively reliable providing that the patient is properly positioned..$^{19,20}$ However, horizontal length measurements in the mandible on DP have been reported to correspond with dry mandible measurements as long as the measurements do not cross the mid-sagittal plane..$^{20}$ Therefore, in this study we selected lesions located in the premolar region, molar region or the ramus of the mandible.

Our study showed that there was a statistically significant difference between the (MSCT) and digital panorama (DP) in detecting the actual size reduction of the cystic lesions resulted from bone deposition after marsupialization. Moreover, MSCT showed statistically significantly higher prevalence of validity and clearly interpretation than modality of the digital panoramic radiography.
The current study was concluded that; evaluation and follow up of the post-marsupialization size reduction progress of mandibular odontogenic cystic lesions reliance solely on digital panoramic radiography might lead to professional decision inaccuracy interrelated to the accurate real size reduction of these lesions. Meanwhile, whenever the surgeon depending on MSCT views they could be ; either terminate the follow up procedures and establish curettage to the remnants of the lesions or continuous post-marsupialization follow up for additional time depending on nearly actual true dimensions.

So the authors recommended that the digital panoramic radiography alone is an insufficient tool for assessment, evaluation and follow up of these treatment modalities of the mandibular cystic lesions. Controversy, we recommended applying MSCT for evaluation of size reduction of the mandibular cystic lesions after marsupialization procedures.

\section{REFERENCES}

1. Partsch C. Uber zwei falle von odontomen. Dtsch Mschr Zahnheilk 1892; 10: $223 \pm 233$.

2- Killey HC, Kay LW, Seward GR. Benign cystic lesions of the jaws, their diagnosis and treatment. 3rd edn. Churchill Livingstone: Edinburgh 1977.

3. Thomas Schlieve, Michael Miloro, and Antonia Kolokythas. Does Decompression of Odontogenic Cysts and Cystlike Lesions Change the Histologic Diagnosis. J Oral Maxillofac Surg. 2014 ,72:1094-1105

4. Zhao Y, Liu B, Han Q, Wang S, Wang Y. Changes in bone density and cyst volume after marsupialisation of mandibular odontogenic keratocysts (keratocystic odontogenic tumors). J Oral Maxillofac Surg 2010; 69:1361-6.

5. L.F.B. de Paulo et al. Treatment of an extensive unicystic ameloblastoma in a7-year-old child: the best approach. British Journal of Oral and Maxillofacial Surgery 53 (2015) 292-294 
6- Dror M. Allon, DMD, Irit Allon, DMD,y Yakir Anavi, DMD,z Ilana Kaplan, DMD. Decompression as a Treatment of Odontogenic Cystic Lesions in Children. J Oral Maxillofac Surg 2015.73:649-654.

7. Tronje G, Welander U, McDavid WD, Morris CR. Image distortion in rotational panoramic radiography. I: general considerations. Acta Radiol Diagn (Stockh) 1981; 22: 295-299.

8. Tronje G, Eliasson S, Julin P, Welander U. Image distortion in rotational panoramic radiography. II: vertical distances. Acta Radiol Diagn (Stockh) 1981; 22: 449-455.

9. Batenburg RHK, Stellingsma K, Raghoebar GM, Vissink A. Bone height measurements on panoramic radiographs: the effect of shape and position of edentulous mandibles. Oral Surg Oral Med Oral Pathol Oral Radiol Endod 1997; 84: 430-435.

10. Larheim TA, Svanaes DB. Reproducibility of rotational panoramic radiography: mandibular linear dimensions and angles. Am J Orthod Dentofacial Orthop 1986; 90: 45-51.

11. Catic A, Celebic A, Valentic-Peruzovic M, Catovic A, Jerolimov V,Ivana M. Evaluation of the precision of dimensional measurements of the mandible on panoramic radiographs. Oral Surg Oral Med Oral Pathol Oral Radiol Endod 1998; 86: 242-248.

12. Cavalcanti MGP, Ruprecht A, Quets J. Progression of maxillofacial squamous cell carcinoma evaluated using computer graphics with spiral computed tomography. Dentomaxillofac Radiol 1999; 28: 238-244.

13. Lindh C, Petersson A, Klinge B. Measurements of distances related to the mandibular canal in radiographs. Clin Oral Implants Res 1995; 6: 96-103.
14- Close LG, Merkel M, Burns DK, Schaefer SD. Computed tomography in the assessment of mandibular invasion by intraoral carcinoma. Ann Otol Rhinol Laryngol 1986; 95: 383-388.

15. Huang CS, Ko WC, Lin WY, Liou EJ, Hong KF, Chen YR. Mandibular lengthening by distraction osteogenesis in children-a one-year follow-up study. Cleft Palate Craniofac J 1999; 36: 269-274.

16. Tharanon W, Sinn DP. Mandibular distraction osteogenesis with multidirectional extraoral distraction device in hemifacial microsomia patients: three-dimensional treatment planning, prediction tracings, and case outcomes. J Craniofac Surg 1999; 10: 202-213.

17- Pogrel MA: Decompression and marsupialization as a treatment for the odontogenic keratocysts. Oral Maxillofac Surg Clin North Am , 200315:415.

18- V Chuenchompoonut, M Ida, E Honda, T Kurabayashi and $\mathrm{T}$ Sasaki. Accuracy of panoramic radiography in assessing the dimensions of radiolucent jaw lesions with distinct or indistinct borders. Dentomaxillofacial Radiology (2003), $32,80-86$ q .

19. Batenburg RHK, Stellingsma K, Raghoebar GM, Vissink A. Bone height measurements on panoramic radiographs: the effect of shape and position of edentulous mandibles. Oral Surg Oral Med Oral Pathol Oral Radiol Endod 1997; 84: 430-435.

20. Catic A, Celebic A, Valentic-Peruzovic M, Catovic A, Jerolimov V, Ivana M. Evaluation of the precision of dimensional measurements of the mandible on panoramic radiographs. Oral Surg Oral Med Oral Pathol Oral Radiol Endod 1998; 86: 242-248. 